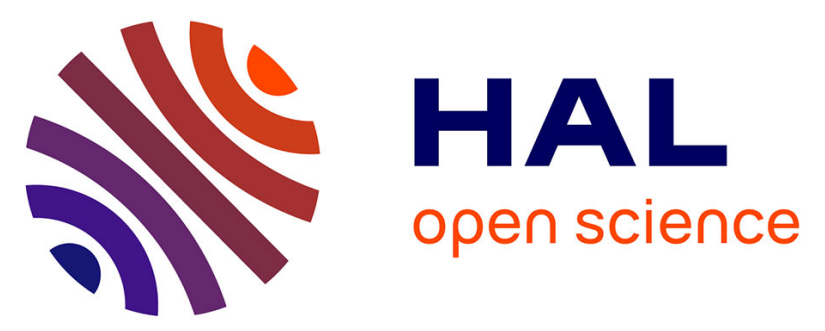

\title{
Early-onset epileptic encephalopathy related to germline PIGA mutations: A series of 5 cases
}

Marie Le Roux, Julien van Gils, Sophie Gueden, Patrick Desbordes de Cepoy, Alec Aeby, Catheline Vilain, Edouard Hirsch, Anne de Saint Martin, Vincent Des Portes, Gaetan Lesca, et al.

\section{To cite this version:}

Marie Le Roux, Julien van Gils, Sophie Gueden, Patrick Desbordes de Cepoy, Alec Aeby, et al.. Earlyonset epileptic encephalopathy related to germline PIGA mutations: A series of 5 cases. European Journal of Paediatric Neurology, 2020, 28, pp.214-220. 10.1016/j.ejpn.2020.06.002 . hal-03477017

\section{HAL Id: hal-03477017 https://hal.science/hal-03477017}

Submitted on 14 Dec 2021

HAL is a multi-disciplinary open access archive for the deposit and dissemination of scientific research documents, whether they are published or not. The documents may come from teaching and research institutions in France or abroad, or from public or private research centers.
L'archive ouverte pluridisciplinaire HAL, est destinée au dépôt et à la diffusion de documents scientifiques de niveau recherche, publiés ou non, émanant des établissements d'enseignement et de recherche français ou étrangers, des laboratoires publics ou privés.

\section{(2)(1) $\$$}

Distributed under a Creative Commons Attribution - NonCommercial - NoDerivatives $\mid 4.0$ 


\title{
$C A C N A 1 A$-associated epilepsy: electroclinical findings and treatment response on seizures in 18 patients.
}

\begin{abstract}
Marie Le Roux ${ }^{\mathrm{a}}{ }_{-}$, Magalie Barth ${ }^{\mathrm{b}}$, Sophie Gueden ${ }^{\mathrm{a}}$, Patrick Desbordes de Cepoy ${ }^{\mathrm{c}}$, Alec Aeby ${ }^{\mathrm{d}}$, Catheline Vilain ${ }^{\overrightarrow{\mathrm{e}}}$, Edouard Hirsch ${ }^{\mathrm{f}}$, Anne de Saint Martin ${ }^{\mathrm{g}}$, Vincent des Portes ${ }^{\mathrm{h}}$, Gaëtan Lesca ${ }^{\mathrm{i}}$, Audrey Riquet ${ }^{j}$, Laurence Chaton ${ }^{\mathrm{k}}$, Nathalie Villeneuve ${ }^{1}$, Laurent Villard ${ }^{\mathrm{m}, \mathrm{n}}$, Claude Cances ${ }^{\mathrm{o}}$, Luc Valton $^{\mathrm{p}, \mathrm{q}}$, Florence Renaldo ${ }^{\mathrm{r}}$, Anne-Isabelle Vermerschs ${ }^{\mathrm{s}}$, Cecilia Altuzarrat, Marie-Ange NguyenMorel $^{\mathrm{u}}$, Julien Van Gils ${ }^{\mathrm{v}}$, Chloé Angelini ${ }^{\mathrm{v}}$, Arnaud Biraben ${ }^{\mathrm{w}}$, Lionel Arnaud ${ }^{\mathrm{x}}$, Florence Riant ${ }^{\mathrm{y}}$ and Patrick Van Bogaert ${ }^{\mathrm{a}, \mathrm{z}}$
\end{abstract}

${ }^{a}$ Department of Pediatric Neurology and Neurosurgery, CHU Angers, France

${ }^{\mathrm{b}}$ Department of Medical Genetics, CHU Angers, France

${ }^{c}$ Department of Pediatric Radiology, CHU Angers, France

${ }^{\mathrm{d}}$ Department of Pediatric Neurology, HUDERF, Bruxelles, Belgium

${ }^{\mathrm{e}}$ Department of Medical Genetics, Erasme Hospital, Bruxelles, Belgium

${ }^{\mathrm{f}}$ Department of Neurology, CHU Strasbourg, France

${ }^{\mathrm{g}}$ Department of Pediatrics, CHU Strasbourg, France

${ }^{\mathrm{h}}$ Department of Pediatric Neurology, Hospices civils de Lyon, Bron, France

${ }^{i}$ Department of Genetics, Hospices civils de Lyon, Bron, France

${ }^{j}$ Department of Pediatric Neurology, CHRU Lille, France

${ }^{\mathrm{k}}$ Department of Neurophysiology, CHRU Lille, France

${ }^{1}$ Department of Pediatric Neurology, Hôpital de La Timone, AP-HM, Marseille, France

${ }^{\mathrm{m}}$ Department of Medical Genetics, Hôpital de La Timone, AP-HM, Marseille, France

${ }^{\mathrm{n}}$ Aix Marseille Univ, Inserm, Marseille Medical Genetics, U1251, Marseille, France.

${ }^{\circ}$ Department of Pediatric Neurology, CHU Purpan, Toulouse, France

${ }^{\mathrm{p}}$ Explorations Neurophysiologiques, CHU Purpan, Toulouse, France

${ }^{\mathrm{q}}$ Centre de Recherche Cerveau et Cognition (CerCo), University of Toulouse, Toulouse F-31300,

France

${ }^{\mathrm{r}}$ Department of Pediatric Neurology, Hôpital Trousseau, Assistance publique-Hôpitaux de Paris,

France

${ }^{\mathrm{s}}$ Department of Neurophysiology, Hôpital Trousseau, Assistance publique-Hôpitaux de Paris, France

${ }^{t}$ Department of Pediatrics, CHU Besançon, France

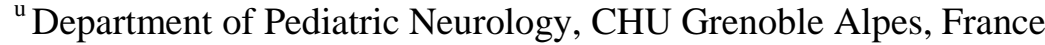

${ }^{v}$ Department of Medical Genetics, CHU Bordeaux Pellegrin, Bordeaux, France

${ }^{\mathrm{w}}$ Department of Neurology, CHU Rennes Pontchaillou, Rennes, France

${ }^{\mathrm{x}}$ Department of Genetics, Hôpital de la Pitie Salpetrière, Assistance publique-Hôpitaux de Paris,

France

${ }^{y}$ Department of Genetics, Groupe hospitalier Saint Louis-Lariboisière, Assistance publique-Hôpitaux de Paris, France

${ }^{\mathrm{z}}$ Laboratoire Angevin de Recherche en Ingénierie des Systèmes (LARIS), Université d'Angers,

France

\section{* Corresponding author:}

Marie Le Roux, CHU Angers, MD

Service de Neurologie Pédiatrique

Bâtiment Robert Debré, CHU et Université d'Angers

4 rue Larrey, 49100 Angers, France 
Phone: 33 (0)2 41354846

e-Mail: Marie.Le-Roux@chu-angers.fr

\section{Abstract}

CACNA1A pathogenic mutations are involved in various neurological phenotypes including episodic ataxia (EA2), spinocerebellar ataxia (SCA6), and familial hemiplegic migraine (FHM1). Epilepsy is poorly documented. We studied 18 patients (10 males) carrying de novo or inherited CACNAIA mutations, with median age of 2,5 years at epilepsy onset. Eight mutations were novel. Two variants known leading to gain of function (GOF) were found in 5 patients. Five other patients had non-sense variants leading to loss of function (LOF). Seizures were most often revealed by either status epilepticus (SE) $(n=8)$, eventually triggered by fever $(n=5)$, or absences/behavioral arrests $(n=7)$. Nonepileptic paroxysmal events were frequent and consisted in recurrent hemiplegic accesses $(n=9)$, jitteriness in the neonatal period $(n=6)$, and ocular paroxysmal events $(n=9)$. Most of the patients had early permanent cerebellar dysfunction $(n=16)$ and early moderate to severe global developmental delay (GDD)/intellectual deficiency (ID) ( $\mathrm{n}=17)$. MRI was often abnormal, with cerebellar $(\mathrm{n}=8)$ and/or cerebral $(n=6)$ atrophy. Stroke-like occurred in 2 cases. Some antiepileptic drugs including topiramate, levetiracetam, lamotrigine and valproate were effective on seizures. Acetazolamide and calcium channel blockers were often effective when used. More than half of the patients had refractory epilepsy. CACNA1A mutation should be evoked in front of 2 main electro-clinical phenotypes that are associated with permanent cerebellar dysfunction and moderate to severe GDD/ID. The first one, found in all 5 patients with GOF variants, is characterized by intractable seizures, early and recurrent $\mathrm{SE}$ and hemiplegic accesses. The second, less severe, found in 5 patients with LOF variants, is characterized by refractory early onset absence seizures.

\section{Key-words :}

CACNA1A, status epilepticus, absence seizure, Lennox-Gastaut syndrome, drug-resistance, strokelike. 


\title{
Highlights :
}

- CACNA1A variants result in 2 different electro-clinical phenotypes: intractable seizures associated with early and recurrent status epilepticus and hemiplegic accesses, and early onset refractory absence seizures.

- Functional studies suggest that the first electro-clinical phenotype is associated with a gain of function, and that the second one is associated with a loss of function.

- Epilepsy related with CACNA1A variants is associated with cerebellar dysfunction and early neurodevelopmental impairment.

- Drug resistance is very frequent in epileptic CACNA1A patients.

\begin{abstract}
Abbreviations : HVA, high-voltage-activated; LOF, Loss of function; EA2, Episodic Ataxia type 2; ACTZ, Acetazolamide; GOF, Gain of function; FHM1, Familial Hemiplegic Migraine type 1; SCA6, Spinocerebellar Ataxia type 6; AHC, Alternating Hemiplegia of Childhood; EIEE, early onset epileptic encephalopathy; AED, anti-epileptic drug; CCBs, calcium channel blockers; SE, status epilepticus; IED, interictal epileptiform discharges; LGS, Lennox-Gastaut syndrome; PTU, paroxysmal tonic upgaze; GDD, global developmental delay; ID, intellectual deficiency; CP, cerebral palsy; GMFCS, Gross Motor Function Classification System; FIRES, Febrile-Infection-Related Epilepsy in School age children Syndrome; ADC, apparent diffusion coefficient; ASL, arterial spin labeling; DEE, epileptic and developmental encephalopathy.
\end{abstract}

\section{Introduction}

Located on chromosome 19 (19p13), CACNA1A gene encodes the principle pore-forming subunit of the P/Q-type calcium channel, alpha-1 (also known as Cav2.1).(1) P/Q-type calcium channels are high-voltage-activated (HVA) calcium channels and are abundantly expressed in the cerebellum, thalamus, cortex and hippocampus, mediating neurotransmission via fast synaptic transmission at central and peripheral nerve terminals.(2) Calcium homeostasis is tightly regulated. Therefore, a minor alteration of tension-gating or receptor 
expression can lead to clinically significant neurological abnormalities, making CACNAIA mutations responsible for rare and heterogeneous neurological diseases.

Loss of function (LOF) mutations of CACNA1A have classically been associated with Episodic Ataxia type 2 (EA2; OMIM 108500), characterized by attacks of cerebellar ataxia and dysarthria classically starting in childhood and responding to acetazolamide (ACTZ). Gain of function (GOF) mutations have been associated with Familial Hemiplegic Migraine type 1 (FHM1; OMIM 141500) characterized by migraine with aura and transient hemiplegic access with an age of onset in childhood or early adulthood.(3) Spinocerebellar Ataxia type 6 (SCA6; OMIM 183086) is another well-known phenotype associated with mutations of the CACNA1A gene, characterized by late onset and slowly progressive cerebellar ataxia. These conditions may overlap. For instances, patients with FHM1 and EA2 often have mild permanent cerebellar symptoms, and patients with SCA6 can display episodic features as seen in EA2. This complicates efforts to define a clear genotype-phenotype correlation. In addition, CACNA1A gene has also been reported with the phenotype of Alternating Hemiplegia of Childhood (AHC).(4)

Epilepsy has also been reported with pathogenic variants of CACNA1A (5-9) but its precise prevalence is unknown in this selected population. The occurrence of seizures is not surprising as voltage-gated $\mathrm{Ca} 2+$ channels are key regulators of neuronal excitability and are important components of ictogenesis.(10) Indeed, studies on murine models of absence seizures showed that aberrant P/Q type channel function results in dysfunction of neurotransmitter release in neocortical neurons and may account for reduced evoked excitability in thalamic neurons. However, data on associated-CACNA1A epilepsy are scarce and heterogeneous in humans. A few cases of early onset epileptic encephalopathy (EIEE) with a pathogenic mutation of the CACNA1A gene are reported on OMIM database (EEIE 42: OMIM entry 617107), but the phenotype of affected patients is poorly characterized.(11,12) 
Though, many questions remain unanswered in CACNA1A-associated epilepsy, including the electro-clinical pictures, the response to anti-epileptic drugs (AED) and the long-term outcome regarding seizure control and neurological comorbidities. Only a few human studies looked at the effectiveness on seizures of usual AED, ACTZ or calcium channel blockers (CCBs) $(4,8,13)$, or tried to make genotype-phenotype correlation.(14)

The aim of this study is to describe the epilepsy spectrum of individuals carrying a pathogenic mutation of CACNA1A who experienced seizures, in order to refine the electro-clinicoradiologic presentation, response to treatment, and long-term outcome for both seizures and psychomotor development.

\section{Methods}

\subsection{Patients}

We conducted a retrospective multicentric study in French and Belgian Hospitals between April 2019 and November 2020.

The inclusion criteria were the identification of a pathogenic variant of CACNA1A and a welldocumented epilepsy, defined by the recurrence of unprovoked seizures. For each patient, both epileptic seizures and syndromes were characterized using the classification of the International League Against Epilepsy (ILAE).(15,16) The clinical data of the patients were assessed using a data collection form filled by the referring clinician (pediatric or adult neurologist) of each patient, based on medical reports. We focused on seizure types, electroencephalography (EEG) abnormalities, psychomotor development, MRI findings and response to treatments, from the beginning of neurological symptoms to the time of the 
inclusion in the study. EEG recordings from 10 patients were reviewed by the first and last authors. EEG reports were available in all cases.

\subsection{Genetic analyses}

DNA was extracted from peripheral blood for all patients and their parents. CACNAIA variants were isolated by whole exome sequencing, NGS panel analysis or CACNA1A gene Sanger sequencing. All identified CACNAIA variants were interpreted according to the American College of Medical Genetics and Genomics standards and guidelines for the interpretation of sequence variants.

\subsection{Ethics}

The Human Research Ethics Committee of CHU Angers approved the study (Project No. 2020/09). All participants or their legal guardians provided written informed consent.

\section{Results}

Eighteen patients (10 males) from 16 families were recruited. Median age at the time of the study was 9,5 years (range 2 to 64 years). Data are summarized in Table 1 .

\subsection{Pregnancy and perinatal characteristics}

Pregnancy was unremarkable in $89 \%(n=16)$. At birth, patients had normal weight, height, head size and adapted well. Case 3 was born at 36 weeks gestation, with a weight of 1900 grams. She adapted well at birth. Case 4 was issued from in vitro fertilization. No data were available for 2 patients (cases 8 and 11). 


\subsection{Seizures and EEG characteristics}

Median age at epilepsy onset was 2,5 years (range: 2 months to 19 years). Electro-clinical data for each individual are summarized in Table 2. None of the cases had a family history of epilepsy not related to CACNA1A. All EEG recordings were obtained during wakefulness. In 14 cases, sleep records were also obtained. Seizures were recorded in 15 cases (83\%).

\subsubsection{Initial presentation}

We distinguished 2 main modes of presentation for seizures. The first one was status epilepticus (SE): bilateral tonic-clonic SE (seizure $>5$ min requiring medication to stop) or focal or absence SE (focal seizure or absence lasting more than 10 minutes). It was found in 8 cases (cases 1,2,3,9,12,13,15 and 16, median age at onset of 12 months), either focal $(n=5)$ with impaired awareness, or generalized $(n=3)$. A motor component was usually reported, mostly consisting in clonic jerks (Fig 2. a). Fever triggered the initial SE in 5 cases. In case 13, encephalitis was initially suspected, based on the electroclinical presentation including triphasic periodic complexes on EEG (Fig 2.e).

The second mode of presentation, found in 7 cases (cases 4,5,7,10,11,17 and 18, median age at onset of 36 months), consisted in storms of short seizures, reported as absences $(n=6)$ or behavioural arrests $(n=1)$, sometimes accompanied by automatisms.

The mode of presentation for seizures was not available for case 8 , and not remarkable in cases 6 and 14 who presented with generalized tonic-clonic seizures.

\subsubsection{Epilepsy course}

The frequency of seizures varied widely. Most patients had daily or weekly seizures. They were focal, generalized, or of unknown onset, but included consciousness impairment in all cases. 
Tonic seizures were reported in 4 cases and recorded in 3 of them, with either focal (frontal or centro-parietal) onset (cases 2 and 12), or generalized onset (case 15).

Behavioural arrest was the prominent feature of seizures in 12 patients. These seizures were generalized in 7 cases, with an ictal pattern of absence seizures, either typical with $3 \mathrm{~Hz}$ spikewaves complexes (cases 5,17 and 18), or atypical (cases 7 and 11) epilepsy course (Fig 2. b). For cases 8 and 10, no ictal recording was available, but we assume that they had absence seizures considering the presence of generalized interictal epileptiform discharges (IED). Focal onset was recorded in 2 of these 12 cases, with temporal or temporo-occipital onset (cases 3 and 4 ). In the remaining 3 cases (case 13, 15 and 16), behavioural arrests were reported but not recorded on EEG, and interictal data were inconclusive.

Myoclonic seizures were reported in 3 cases and recorded in 1 of them, with ictal generalized poly-spike waves.

Seizures occurred during sleep in 5 patients. Three of them (cases 12, 15 and 16) had predominantly nocturnal tonic seizures that started between 4 and 9 years and were associated with other types of seizures, including tonic-clonic and atonic seizures.

Triggers for seizures were often found (fever, stress, hormonal changes, minor head trauma). Patients that initially presented with focal or generalized SE often recurred with about 2-3 SE a year during childhood. This tended to decrease with advanced age. In a few cases, SE lasted more than 30 minutes and was refractory, but in most cases SE stopped after 1 to 3 drugs.

Concerning interictal recordings, excessive slow activity was present in most patients. Generalized, focal or multifocal IED were recorded in 15 patients $(83 \%)$, consisting in sharp waves or spike-waves complexes. In cases 12 and 15, spike-wave complexes with anterior predominance were activated by sleep, and diffuse fast rhythms during sleep were recorded in cases 12 and 16.

\subsubsection{Epilepsy types and syndromes}


Epilepsy types were classified as generalized $(44 \%, n=8)$, focal $(17 \%, n=3)$ or combined generalized and focal $(33 \%, \mathrm{n}=6)$. In one case, epilepsy type remained unknown.

For case 1, Dravet syndrome was evoked on the initial presentation as he presented a febrile focal SE at the age of 7 months. Patients 12, 15 and 16 were diagnosed as Lennox-Gastaut syndrome (LGS), considering nocturnal tonic seizures and EEG findings with generalized spike and waves at $2 \mathrm{~Hz}$.

\subsection{Response of epilepsy to treatments}

Treatment response was assessed according to the following classification: seizure-free, seizure reduction (patients achieving more than 50\% reduction in seizure frequency) or no effects (defined by less than $50 \%$ reduction of seizures). The effectiveness of each drug is summarized in Table 3, and global trends in medication effectiveness are expressed in Figure 1.

For Topiramate (TPM), $89 \%$ of effectiveness was found, including one patient who became seizure-free a few months after its introduction. About 50-60\% of the patients were found as improved by Levetiracetam (LEV), Lamotrigine (LTG) and Valproate (VPA), including 2 patients who became seizure-free under LEV. Even if observed in few patients, Phenobarbital (PB), Lacosamide and Oxcarbazepine (OXC) also improved seizure control. Felbamate seems to have aggravated seizures in case 16.

Concerning ACTZ and CCBs (Flunarizine and Verapamil), trends were observed on very few patients. ACTZ made case 2 seizure-free, and improved seizures in 2 additional cases. CCBs reduced SE and hemiplegic accesses frequency in case 13. No effect emerged from the use of pyridoxine.

Neither Ketogenic Diet (KD) nor Vagus Nerve Stimulation (VNS), tried in 4 and 3 patients, respectively, showed significant effect. 
According to the Brodie's classification for long term epilepsy outcome (17), 61\% (n=11) had ongoing refractory seizures, and still suffered from daily or weekly seizures, $11 \%(n=2)$ had a fluctuating course (periods of seizure freedom of more than 12 months interspersed with relapses), $11 \%(\mathrm{n}=2)$ had delayed seizure freedom (seizures not immediately controlled by medication, but became seizure-free at some point after 6 months), and 17\% ( $n=3)$ had early seizure freedom (seizure-free within 6 months of starting treatment).

\subsection{Non epileptic paroxysmal events}

Transient and flaccid hemiplegic accesses were reported in 9 cases (50\%). In addition, 8 of them had episodes of prolonged confusion, major hypotonia, and intense lethargy. These episodes were eventually preceded or followed by an episode of SE. Hemiplegic accesses started in early childhood with a median age of 2 years (range: 7 months to 7,5 years). Except for subject 3 who experienced accesses several times a week, hemiplegic accesses usually occurred about twice a year, sometimes more during the first years of life, then tended to decrease with age. In 7 cases, fever was the main trigger. The duration of hemiplegic attacks varied widely, ranging from a few minutes to months, resulting in this situation in a prolonged drowsiness and motor deficit (subjects 1,2 and 13). In the acute phase, continuous hemispheric slow theta or delta activity was recorded on EEG (Fig 2. c). This slow pattern could persist for months, consistent with the clinical deficits (Fig 2. d). When present, seizures were usually ipsilateral to the hemiplegic accesses.

Only one patient (patient 3) complained of headaches that occurred in the interictal period and responded to nonsteroidal anti-inflammatory drugs. Migraine was not reported. 
Paroxysmal cerebellar ataxia was found in 10 cases $(55 \%)$, characterized by recurrence of acute episodes of major unsteadiness, limb incoordination, dysarthria, vertigo and nausea or vomiting.

Nine patients had paroxysmal non-epileptic movements. For 6 of them, the movements occurred in the newborn period, consisting in jitteriness or myoclonus. These newborns were reported as irritable and presented agitation. Three patients had video-EEG that confirmed the non-epileptic nature of these movements (Fig 2.f).

Ocular paroxysmal events were reported in half of the cases. Early paroxysmal gaze-evoked nystagmus was found in 7 patients and persisted at long-term. Paroxysmal tonic upgaze (PTU) was diagnosed in 2 patients, consisting in episodic vertical eyes movements.

\subsection{Neurodevelopmental and general outcome}

The first neurological features were reported at a median age of 4 months (range: 1 day to 36 months). Global developmental delay (GDD) and hypotonia were the presenting features in 10 patients $(55 \%)$. In 6 cases, the first neurological signs were non-epileptic paroxysmal events. Seizures were the first neurological manifestations in the two remaining cases.

GDD was present prior to the onset of seizures in most of the cases $(n=16)$. Intellectual deficiency (ID), defined as impaired intellectual skills and limited adaptive behavior with onset during childhood, was present in all but one case and was severe in $61 \%$ of them, with nearly absence of expressive language. A component of dysarthria was well documented in only one case (patient 2). Five patients had autistic features beyond what can be expected from ID combined with neurological impairment.

Most of the patients had early motor disability, with a combination of ataxia and hypotonia $(\mathrm{n}=16)$. In 10 patients, the motor dysfunction remained stable, fitting with the definition of 
cerebral palsy $(\mathrm{CP})$, but in the 6 remaining patients it progressively worsened with time. In one case (patient 13), regression was acute after an extended stroke-like episode as this patient lost independent walking and showed cognitive deterioration. Ataxia was often associated with other motor disabilities: unilateral or bilateral spasticity $(n=8)$, dystonia $(n=5)$, or choreoathetosis $(n=2)$. At the time of the study and according to the Gross Motor Function Classification System (GMFCS), patients were classified as level 1 (22\%), level 2 (11\%), level $3(28 \%)$, level $4(17 \%)$ and level $5(11 \%)$. Independent walk was acquired in 8 patients (44\%), with a median age of 2 years (range from 1 to 4,5 years, excluding a missing data). Evolution to microcephaly was not observed.

All but one patient, who benefited from a gastrostomy, were orally fed.

Importantly, case 14 died at the age of 10 years following a SE in a context of persistence drowsiness, dysautonomic features and central hyperthermia.

\subsection{Genetic features}

Genetic features for each individual are summarized in Table 1 and detailed in supplementary materials $(S 1)$.

The 18 patients belong to 16 families. Median age at genetic diagnosis was 6 years (range: 1 to 58 years). Thirteen distinct variants were identified in the 16 index cases. Eight were missense variants, 5 were non-sense. Eight mutations were not previously reported. All were absent from gnomAD database and were predicted as deleterious in silico tools.

Nine patients carried a de novo mutation and 7 patients inherited their mutation from a parent. The mode of inheritance remained unknown in the last 2 cases: the father of case 5 died from a non-neurological disease, and the parents of case 8 could not be screened. 
A family was included, the father and his two children (cases 6,7 and 8). Case 10 carried a pathogenic mutation inherited from his mother, who had paroxysmal ataxic episodes during childhood. They belonged to a large family previously reported in whom the missense variant segregated with the disease in affected members with a heterozygous missense pathogenic variant. (18) Cases 17 and 18 inherited the mutation from their epileptic mothers. These 2 mothers had a history of epilepsy that was poorly documented, as well as a history of migraine in one of them. Mutations of patients 9 and 11 were inherited from their asymptomatic father. Patient 12 presented in addition a de novo duplication on $5 \mathrm{q} 23.2$ that was not considered as deleterious.

All missense variants were located in segments that form the pore of the Cav2.1 channel (S4, S5, S6 or the P-loop between S5 and S6). Functional studies were available for 5 patients (cases 2,3,12,13 and 16) carrying 2 different variants leading to GOF mutations in humans (12) or murine models.(19) These 5 cases are among the 8 cases that presented as status epilepticus. Among the 4 patients carrying the c.2137G>A / p.(Ala713Thr) variant, 2 patients (cases 12 and 16) had Lennox-Gastaut syndrome. Thus, all 5 patients with variations leading to GOF and severe phenotype had de novo mutation. Non-sense variants, leading to LOF, were found in 5 of the 7 cases that presented absence seizures.

\subsection{MRI data}

MRI data were available in all but one case (case 7) and are summarized in Table 3.

Abnormalities were reported in 10 cases. The most common abnormality was progressive cerebellar atrophy (Fig 3. a-c), reported in 8 cases (44\%). Six patients had cerebral atrophy. Cases 1, 9 and 13 showed recurrent ischemic strokes that were well documented on serial 
MRI. For patients 1 and 13, lesions crossed vascular territories, corresponding to stroke-like lesions 


\section{Discussion}

This is the largest cohort focusing on the epilepsy spectrum in patients with CACNAIA pathogenic mutation, including responses to treatments, as available literature only concerns case reports $(4,5,13,20,21)$ or small series $(6,7,12)$. The largest series that has been reported so far concerned 14 patients.(9)

We found that epilepsy usually started in infancy or early childhood, and that most patients fitted with one of two following electro-clinical phenotypes. The first one, found in 7 patients (cases $1,2,3,12,13,15,16)$ fulfilled the following criteria: (1) Early episodes of SE, often triggered by fever, followed by generalized or focal intractable seizures; (2) Early motor cerebellar deficit, stable in some patients, fitting with the definition of $\mathrm{CP}$, but that could also worsen in others and was associated with acquired pyramidal and/or extra-pyramidal signs; (3) Severe GDD/ID; (4) Neonatal hyperexcitability with jitteriness or myoclonus, that could be difficult to differentiate from epileptic seizures without video-EEG recording; (5) Hemiplegic accesses with consciousness impairment, often triggered by fever, starting in infancy or childhood, with hemispheric slowing on EEG. Absence seizures were not recorded in any of them. The second electro-clinical phenotype, less severe, included 7 patients (cases $5,7,8,10,11,17,18)$ that all presented: (1) Generalized epilepsy with typical or atypical early onset refractory absences seizures; (2) Moderate to severe GDD/ID; (3) Early and stable cerebellum dysfunction. The other 4 patients of this cohort did not fit with any of these 2 phenotypes.

The first and more severe electro-clinical phenotype overlaps with the AHC syndrome $(4,22-$ 24), defined as a syndrome with multiple genetic aetiologies, including CACNA1A.(23) Indeed, patients presented early hemiplegic accesses, cerebellar, pyramidal and/or extrapyramidal signs, and paroxysmal ocular events. Similarly, triggers are usually found in AHC, 
as well as the trends for a decrease of hemiplegic accesses with age. However, epilepsy is not at the foreground in classical AHC. Moreover, our patients usually experienced longer lasting hemiplegic accesses compared to what is described in classical AHC (5) and sleep did not improve symptoms. In some of these patients, who had an encephalitis-like presentation followed by intractable seizures, the diagnosis of Febrile-Infection-Related Epilepsy in School age children Syndrome (FIRES) could be evoked.(25) Prior GDD and younger age at onset are clues for differential diagnosis. Dravet syndrome could also be evoked in front of the initial presentation of a fever-triggered focal SE occurring in the first year of life, but early and severe motor handicap as seen in our patients is unusual in Dravet syndrome, as well as interictal abnormalities that were already present on EEGs performed early in the course of the epileptic disorder. Three patients had LGS. Two of them carried the (p.Ala713Thr) mutation that has already been reported in other patients with epilepsy $(11,12,26)$, including a case of LGS. (12) All cases that belong to this first electro-clinical phenotype were carrying a sporadic missense variant. Variants for which functional studies were available led to GOF mutations.(12,19) Increased susceptibility to seizures seems to be related to a particularly low cortical spreading depression (CSD) threshold and a strong tendency to respond with multiple CSD events due to the GOF increasing P/Q channel currents and enhancing neurotransmitter release.(8) At a protein level, these likely GOF mutations led to variants that were localized on the III and IV domains, as previously described (8), and also concerned the transmembrane domain.

The second electro-clinical phenotype was characterized by refractory early onset absences seizures. A few cases of $C A C N A 1 A$-associated typical or atypical absence seizures have been previously reported $(6,7,9,27)$. Studies suggest that P/Q channels have an essential role in maintain normal thalamocortical oscillations. The loss of their functionality, by inducing functional imbalance, leads to absence seizures in a mouse model.(28) Non-sense mutations 
were found in most of the cases, leading to LOF. This is in line with previous reported cases of $C A C N A 1 A$-associated absence seizures. $(7,9)$ Regarding the phenotype of these 7 patients, including cerebellar symptoms and GDD, frequent neurological non-epileptic paroxysmal events, the early age at absence seizures onset and the associated EEG findings, a GLUT-1 deficiency syndrome could be evoked.(29) Clue for differential diagnosis is the normal level of glucose in the CSF.

Whether epilepsy was directly related to the genetic mutation in all patients is questionable as 6 of them had structural lesions on MRI that could be considered as epileptogenic, i.e. cortical atrophy, cortical ischemic lesions and hippocampal sclerosis. However, in all but one case, there were no clear spatial relationships between the localisation of the lesions and the main epileptic foci. Brain damages are considered as resulting from SE or from prolonged hemispheric swelling that may occur at the acute phase of the hemiplegic access (30) (Fig 3. d), leading to cytotoxic oedema. In our 3 patients that experienced ischemic strokes, MRI findings were consistent with stroke-like lesions in 2 cases, as they crossed vascular territories and showed at the acute stage hyperintensity on T2WI and DWI (Fig 3. g-i). Concomitant hyperperfusion in arterial spin labeling (ASL) was also reported (31) but unfortunately ASL was not available in our 2 stroke-like cases. In case 13, the first MRI was performed at the very early stage of an hemiplegic access in a context of a stroke alert, explaining the absence of change on the ADC map (Fig 3. d-f).(32) Of note, the mutation found in one of this case was previously reported in a case who experienced stroke-like episodes.(19) Altogether, these findings expand the clinical spectrum of CACNA1A mutations, suggesting a clinical continuum between hemiplegic access, epilepsy and stroke-like.

CACNA1A is considered as a cause of epileptic and developmental encephalopathy (DEE) after reports of patients with early and severe epilepsy, with migrating focal seizures in some patients. (11) No patients from this cohort presented this early epileptic phenotype. 
Classifying patients of this cohort within the DEEs is debatable. Indeed, according to this concept (16), cognitive impairment results from a combination of a developmental component and an epileptic component, suggesting a specific role of epilepsy to cognitive impairments, partially reversible if the epileptic component is appropriately treated. It is likely that epilepsy played a role in the neurological deterioration in those patients who presented recurrent convulsive SE and associated lesions on MRI, as suggested by other authors. $(6,33)$ However, this concerns only a subgroup of patients, and cognitive improvement in conjunction with better seizure control was not documented in any patient. Therefore, the real contribution of epilepsy in the cognitive dysfunction remains undetermined in a lot of patients.

Despite the high rate of pharmaco-resistant cases, we found that TPM, LEV, LTG and VPA were the most helpful AED to control seizures. It should be noted that these drugs have some blocking action on HVA calcium channels. Indeed, TPM, LEV, LTG, gabapentine, OXC and $\mathrm{PB}$, although mainly acting on sodium channels or on GABA receptors, are also blockers of the P/Q calcium channels.(8,34-37) Therefore, these AEDs should be useful in patients carrying GOF mutations. On the other hand, VPA and ethosuximide act on L- and T-types voltage dependent calcium channels. $(13,34,38)$ This could in turn be helpful in case of LOF of the P/Q calcium channels.(39) However, we were unable to assess the effectiveness of these drugs according to the functional consequences of the variants. Concerning other calcium blockers, both flunarizine and verapamil were reported to be useful on hemiplegic accesses and prolonged seizures.(40) We confirmed this finding in one case. The efficacy of ACTZ on seizures has already been reported in a case.(41) This was confirmed in one refractory case of our cohort who became seizure-free under ACTZ. However, this drug was infrequently used in our cohort. Clearly more attention should be paid on the effect of ACTZ as part of the effectiveness of TPM could be related to a carbonic anhydrase inhibitory effect. Pyridoxine was reported as useful in a patient with $C A C N A 1 A$-associated absence seizures 
(42), but this was not confirmed in our cohort. A clear limitation of this study was the retrospective design that increased the risk of bias in the assessment of the various treatments used. Definitely, further research is needed in order to better understand the underpinning pharmacological mechanisms of all these drugs in order to make prospective rational trials according to the functional consequences of the mutations in epileptic patients carrying a pathogenic variant of CACNAIA.

Treatments of acute conditions deserves special comments, as CACNA1A encephalopathy may be a life-threatening condition, as illustrated by one case from this cohort who died in a context of central hyperthermia following SE. Such a fatal issue has already been reported in a 5-year-old girl.(43) In this situation, acute treatments aimed at decreasing temperature and reducing swelling should be considered, especially a combination of verapamil, dexamethasone and hypertonic solution.(44) However, all these treatments are not always successful, stressing the need to better understand the pathophysiology of CACNAIAassociated brain lesions. Moreover, Sudden Unexpected Death in epilepsy models suggests that death-related CACNA1A mutation could have various pathophysiological mechanisms.(45)

\section{Conclusion}

The phenotype of CACNAIA-associated epilepsy is very broad and usually severe. Most patients show permanent cerebellar dysfunction and moderate to severe GDD/ID associated with either early hemiplegic accesses, recurrent SE and intractable seizures that may evolve to Lennox-Gastaut syndrome, or refractory early onset absence seizures that could evoke a GLUT-1 deficiency syndrome. 
Despite a high rate of refractory cases, some therapeutic options including AEDs partly acting on calcium channels, acetazolamide and CCBs may improve seizure control. However, treatment remains disappointing in a lot of patients.

\section{Declaration of competing interest}

None of the authors has any conflict of interest to disclose.

\section{Acknowledgements}

We are indebted to the patients and their families for participation in this study. This research did not receive any specific grant from funding agencies in the public, commercial, or not-forprofit sectors.

\section{References}

1. Ophoff RA, Terwindt GM, Vergouwe MN, van Eijk R, Oefner PJ, Hoffman SMG, et al. Familial Hemiplegic Migraine and Episodic Ataxia Type-2 Are Caused by Mutations in the Ca2+ Channel Gene CACNL1A4. Cell. 1996 nov;87(3):543- 52.

2. Pietrobon D. CaV2.1 channelopathies. Pflügers Archiv. 2010 jul;460(2):375- 93.

3. Tournier-Lasserve E. CACNA1A mutations. Neurology. 1999 Jul;53(1):3- 3.

4. de Vries B, Stam A, Beker F, van den Maagdenberg A, Vanmolkot K, Laan L, et al. CACNA1A Mutation Linking Hemiplegic Migraine and Alternating Hemiplegia of Childhood. Cephalalgia. 2008 Aug;28(8):887- 91.

5. Ducros A, Denier C, Joutel A, Cecillon M, Lescoat C, Vahedi K, et al. The Clinical Spectrum of Familial Hemiplegic Migraine Associated with Mutations in a Neuronal Calcium Channel. N Engl J Med. 2001 Jul 5;345(1):17-24.

6. Damaj L, Lupien-Meilleur A, Lortie A, Riou É, Ospina LH, Gagnon L, et al. CACNA1A haploinsufficiency causes cognitive impairment, autism and epileptic encephalopathy with mild cerebellar symptoms. Eur J Hum Genet. 2015 Nov;23(11):1505- 12.

7. Imbrici P. Dysfunction of the brain calcium channel CaV2.1 in absence epilepsy and episodic ataxia. Brain. 2004 Dec;127(Pt 12):2682-92. 
8. Prontera P, Sarchielli P, Caproni S, Bedetti C, Cupini L, Calabresi P, et al. Epilepsy in hemiplegic migraine: Genetic mutations and clinical implications. Cephalalgia. 2018 Feb;38(2):361-373.

9. Rajakulendran S, Graves TD, Labrum RW, Kotzadimitriou D, Eunson L, Davis MB, et al. Genetic and functional characterisation of the P/Q calcium channel in episodic ataxia with epilepsy: Variation of CACNA1A in episodic ataxia and epilepsy. J Physiol. 2010 Jun 1;588(Pt 11):1905-13.

10. Khosravani H, Zamponi GW. Voltage-Gated Calcium Channels and Idiopathic Generalized Epilepsies. Physiol Rev. 2006 Jul;86(3):941-66.

11. Myers CT, McMahon JM, Schneider AL, Petrovski S, Allen AS, Carvill GL, et al. De Novo Mutations in SLC1A2 and CACNA1A Are Important Causes of Epileptic Encephalopathies. Am J Hum Genet. 2016 Aug 4;99(2):287-98.

12. Jiang X, Raju PK, D’Avanzo N, Lachance M, Pepin J, Dubeau F, et al. Both gain- offunction and loss- of- function de novo CACNA $1 A$ mutations cause severe developmental epileptic encephalopathies in the spectrum of Lennox- Gastaut syndrome. Epilepsia. 2019 Sep;60(9):1881-1894.

13. Byers HM, Beatty CW, Hahn SH, Gospe SM. Dramatic Response After Lamotrigine in a Patient With Epileptic Encephalopathy and a De Novo CACNA1A Variant. Pediatric Neurology. juill 2016;60:79- 82.

14. Lv N, Qu J, Long H, Zhou L, Cao Y, Long L, et al. Association study between polymorphisms in the CACNA1A, CACNA1C, and CACNA1H genes and drugresistant epilepsy in the Chinese Han population. Seizure. 2015 Aug;30:64-9.

15. Fisher RS, Cross JH, D'Souza C, French JA, Haut SR, Higurashi N, et al. Instruction manual for the ILAE 2017 operational classification of seizure types. Epilepsia. 2017 Apr;58(4):531-542.

16. Scheffer IE, Berkovic S, Capovilla G, Connolly MB, French J, Guilhoto L, et al. ILAE classification of the epilepsies: Position paper of the ILAE Commission for Classification and Terminology. Epilepsia. 2017 Apr;58(4):512-521.

17. Kwan P, Brodie MJ. Definition of refractory epilepsy: defining the indefinable? Lancet Neurol. 2010 Jan;9(1):27-9.

18. Angelini C, Van Gils J, Bigourdan A, Jouk P-S, Lacombe D, Menegon P, et al. Major intra-familial phenotypic heterogeneity and incomplete penetrance due to a CACNA1A pathogenic variant. Eur J Med Genet. 2019 Jun;62(6):103530.

19. Knierim E, Leisle L, Wagner C, Weschke B, Lucke B, Bohner G, et al. Recurrent Stroke Due to a Novel Voltage Sensor Mutation in $\mathrm{Ca}_{\mathrm{v}} 2.1$ Responds to Verapamil. Stroke. 2011 Feb;42(2):e14-7.

20. Jouvenceau A. Human epilepsy associated with dysfunction of the brain P/Q-type calcium channel. Lancet. 2001 Sep 8;358(9284):801-7. 
21. Beauvais K, Cavé-Riant F, De Barace C, Tardieu M, Tournier-Lasserve E, Furby A. New CACNA1A Gene Mutation in a Case of Familial Hemiplegic Migraine with Status epilepticus. Eur Neurol. 2004;52(1):58-61.

22. Uchitel J, Helseth A, Prange L, McLean M, Ghusayni R, Sachdev M, et al. The epileptology of alternating hemiplegia of childhood. Neurology. 2019 Sep 24;93(13):e1248-e1259.

23. Kansagra S, Mikati MA, Vigevano F. Alternating hemiplegia of childhood. Handb Clin Neurol. 2013;112:821-6.

24. García Segarra N, Gautschi I, Mittaz-Crettol L, Kallay Zetchi C, Al-Qusairi L, Van Bemmelen MX, et al. Congenital ataxia and hemiplegic migraine with cerebral edema associated with a novel gain of function mutation in the calcium channel CACNA1A. J Neurol Sci. 2014 Jul 15;342(1-2):69-78.

25. Mikaeloff Y, Jambaqué I, Hertz-Pannier L, Zamfirescu A, Adamsbaum C, Plouin P, et al. Devastating epileptic encephalopathy in school-aged children (DESC): A pseudo encephalitis. Epilepsy Res. 2006 Apr;69(1):67-79.

26. Balck A, Hanssen H, Hellenbroich Y, Lohmann K, Münchau A. Adult-onset ataxia or developmental disorder with seizures: two sides of missense changes in CACNA1A. J Neurol. 2017 Jul;264(7):1520-1522.

27. Jung J, Testard H, Tournier-Lasserve E, Riant F, Vallet A-E, Berroir S, et al. Phenotypic Variability of Episodic Ataxia Type 2 Mutations: A Family Study. Eur Neurol. 2010;64(2):114-6.

28. Miao Q-L, Herlitze S, Mark MD, Noebels JL. Adult loss of Cacna1a in mice recapitulates childhood absence epilepsy by distinct thalamic bursting mechanisms. Brain. 2020 Jan 1;143(1):161-174.

29. Leen WG, Klepper J, Verbeek MM, Leferink M, Hofste T, van Engelen BG, et al. Glucose transporter-1 deficiency syndrome: the expanding clinical and genetic spectrum of a treatable disorder. Brain. 2010 Mar;133(Pt 3):655-70.

30. Pelzer N, Hoogeveen ES, Ferrari MD, Poll-The BT, Kruit MC, Terwindt GM. Brain atrophy following hemiplegic migraine attacks. Cephalalgia. 2018 May;38(6):11991202.

31. Li X, Wang Y, Wang Z, Lu J, Xu Y, Ye J, et al. Comparison of magnetic resonance spectroscopy (MRS) with arterial spin labeling (ASL) in the differentiation between mitochondrial encephalomyopathy, lactic Acidosis, plus stroke-like episodes (MELAS) and acute ischemic stroke (AIS). . J Clin Neurosci. 2018 Sep;55:65-70.

32. Finsterer J, Wakil SM. Stroke-like episodes, peri-episodic seizures, and MELAS mutations. Eur J Paediatr Neurol. 2016 Nov;20(6):824-829.

33. Humbertclaude V, Riant F, Krams B, Zimmermann V, Nagot N, Annequin D, et al. Cognitive impairment in children with CACNA $1 A$ mutations. Dev Med Child Neurol. 2020 Mar;62(3):330-337. 
34. Rogawski MA, Löscher W. The neurobiology of antiepileptic drugs. Nat Rev Neurosci. 2004 Jul;5(7):553-64.

35. Pisani A, Bonsi P, Martella G, De Persis C, Costa C, Pisani F, et al. Intracellular Calcium Increase in Epileptiform Activity: Modulation by Levetiracetam and Lamotrigine. Epilepsia. 2004 Jul;45(7):719-28.

36. Martella G, Costa C, Pisani A, Cupini L, Bernardi G, Calabresi P. Antiepileptic Drugs on Calcium Currents Recorded from Cortical and PAG Neurons: Therapeutic Implications for Migraine. Cephalalgia. 2008 Dec;28(12):1315-26.

37. Stefani A, Pisani A, Murtas M, Mercuri NB, Marciani MG, Calabresi P. Action of GP 47779, the Active Metabolite of Oxcarbazepine, on the Corticostriatal System. II. Modulation of High-Voltage-Activated Calcium Currents. Epilepsia. 1995 Oct;36(10):997-1002.

38. Kito M, Maehara M, Watanabe K. Antiepileptic drugs - calcium current interaction in cultured human neuroblastoma cells. Seizure. 1994 Jun;3(2):141-9.

39. Zamponi GW. Targeting voltage-gated calcium channels in neurological and psychiatric diseases. Nat Rev Drug Discov. 2016 Jan;15(1):19-34.

40. Yu W, Horowitz SH. Familial hemiplegic migraine and its abortive therapy with intravenous verapamil. Neurology. 2001 Nov 13;57(9):1732-3.

41. Guerin AA, Feigenbaum A, Donner EJ, Yoon G. Stepwise Developmental Regression Associated With Novel CACNA1A Mutation. Pediatr Neurol. 2008 Nov;39(5):363-4.

42. Du X, Chen Y, Zhao Y, Luo W, Cen Z, Hao W. Dramatic response to pyridoxine in a girl with absence epilepsy with ataxia caused by a de novo CACNA1A mutation. Seizure. 2017 Feb;45:189-191.

43. Gauquelin L, Hawkins C, Tam EWY, Miller SP, Yoon G. Pearls \& Oy-sters: Fatal brain edema is a rare complication of severe CACNA1A-related disorder. Neurology. 2020 Apr 7;94(14):631-634.

44. Camia F, Pisciotta L, Morana G, Schiaffino MC, Renna S, Carrera P, et al. Combined early treatment in hemiplegic attacks related to CACNA1A encephalopathy with brain oedema: Blocking the cascade? Cephalalgia. 2017 Oct;37(12):1202-1206.

45. Loonen ICM, Jansen NA, Cain SM, Schenke M, Voskuyl RA, Yung AC, et al. Brainstem spreading depolarization and cortical dynamics during fatal seizures in Cacnala S218L mice. Brain (2019) 142:412-25.

\section{Legends of figures}

\section{Fig. 1.}

Therapeutic profiles on seizures in CACNA1A pathogenic mutations.

VPA, Sodium Valproate ; LTG, Lamotrigine ; LEV, Levetiracetam ; TPM, Topiramate ; PB, Phenobarbital ; CBZ, Carbamazepine ; OXC, Oxcarbamazepine ; ESM, Ethosuximide ; BZD, 
Benzodiazepine ; LCS, Lacosamide ; ZNS, Zonisamide ; CCBs, Calcium Channel Blockers (Flunarizine or Verapamil) ; ACTZ, Acetazolamide ; KD, Ketogenic Diet ; VNS, Vagus Nerve Stimulation.

\section{Fig. 2.}

Examples of EEG patterns in epileptic patients with CACNA1A pathogenic mutations. Cases 1 (a,c), 11 (b) and 13 (d-f).

(a): Left occipital spike-waves discharge during a right clonic SE. (b): Diffuse 2,5Hz spikewaves discharge concomitant with behavioural arrest, consistent to an atypical absence seizure. (c): Right hemispheric delta activity concomitant with persistent consciousness impairment and left hemiplegia, corresponding to a left hemiplegic access. Note the left temporo-occipital focus, consistent to a previous stroke in this case. (d): Right-lateralized theta rhythmic activity persisting a month after a left hemiplegic attack. (e): Left frontotemporal delta activity with triphasic complexes during a first hemiplegic access with "encephalitis-like" presentation. (f): Episode of bilateral limb jerks recorded on surface EMG, with slow left-sided rhythmic activity but absence of epileptiform discharges, corresponding to non-epileptic movements.

\section{Fig. 3.}

MRI findings in epileptic patients with CACNA1A pathogenic mutations.

Progressive cerebellar atrophy on three T1 sagittal images performed at the age of 1 (a), 2 (b) and 4 years (c) in case 1. Stroke-like lesions in case 13 (d-i). Axial images performed at the subacute phase of a right HM attack (d-f), showing left cortical hyperintensity on FLAIR (d) and DWI (e) corresponding to edema but without signal change on the ADC map (f). Axial images performed 7 days latter (g-i), considering persistent right hemiparesis and homolateral seizures. FLAIR showed left cortical hemispheric hyperintensity (g), and DWI showed left lenticulo-caudal, putaminal and parietal cortical hyperintensities that crossed vascular territories (h) with concomitant signal reduction ranges on the ADC map (i). 

Table 1: Patients clinical and genetic features. (more details in Supplementary Material S1)

\begin{tabular}{|c|c|c|c|c|c|c|c|c|c|}
\hline $\begin{array}{l}\text { Patient, } \\
\text { Gender, Age } \\
\text { at the time of } \\
\text { the study (y) }\end{array}$ & $\begin{array}{c}\text { Mutation } \\
\text { (NM_001127221.1) }\end{array}$ & $\begin{array}{c}\text { Functional } \\
\text { effect }\end{array}$ & Inheritance & $\begin{array}{c}\text { First } \\
\text { neurological } \\
\text { event (Age) }\end{array}$ & MRI & $\begin{array}{l}\text { GDD } \\
/ \text { ID }\end{array}$ & $\begin{array}{l}\text { GMFCS } \\
\text { status }\end{array}$ & $\begin{array}{l}\text { Non epileptic abnormal } \\
\text { movements, HA (age at } \\
\text { onset), PA }\end{array}$ & $\begin{array}{c}\text { Additionnal: } \\
\text { - neurological findings } \\
\text { - ophtalmological findings }\end{array}$ \\
\hline 1, Ma, 6 & c. $5083 \mathrm{G}>\mathrm{C} \ddagger$ & UNK & de novo & $\begin{array}{l}\text { Jitteriness } \\
\text { (10days) }\end{array}$ & $\begin{array}{l}\text { Progressive cerebellar atrophy (Fig } 3 \text {. } \\
\text { a-c), cerebral atrophy, right lenticulo- } \\
\text { striatal and occipital stroke sequels }\end{array}$ & $\mathrm{S}$ & $\mathrm{V}$ & $\begin{array}{l}\text { Tremor/myoclonus/choreo- } \\
\text { athetosis, 7Mo, Yes }\end{array}$ & $\begin{array}{c}\text { Hypotonia, pyramidal signs, dystonia; gaze-evoked } \\
\text { nystagmus }\end{array}$ \\
\hline 2, Ma, 8 & c. $2137 \mathrm{G}>\mathrm{A}$ & GOF & de novo & Jitteriness (1day) & $\begin{array}{l}\text { Progressive cerebellar atrophy } \\
\text { (vermis), cerebral atrophy, } \\
\text { hippocampal sclerosis }\end{array}$ & $\mathrm{S}$ & III & Tremor, $17 \mathrm{Mo}$, Yes & $\begin{array}{l}\text { Hypotonia, cerebellar ataxia, pyramidal signs, ASD; } \\
\text { gaze-evoked nystagmus }\end{array}$ \\
\hline $3, \mathrm{Fe}, 4,5$ & c. $2137 \mathrm{G}>\mathrm{A}$ & GOF & de novo & $\begin{array}{l}\text { Jitteriness } \\
\text { (10days) }\end{array}$ & $\mathrm{N}(1 \mathrm{y})$ & $\mathrm{S}$ & III & Dyskinesia, 24Mo, Yes & $\begin{array}{c}\text { Hypotonia, pyramidal signs, dystonia; PTU, } \\
\text { strabismus }\end{array}$ \\
\hline $4, \mathrm{Fe}, 2,5$ & c. $2006 \mathrm{~A}>\mathrm{C} \$$ & UNK & de novo & Hypotonia (3Mo) & $\mathrm{N}(7 \mathrm{Mo})$ & $\mathrm{S}$ & IV & Athetosis, No, Yes & Hypotonia, central deafness; abnormal visual contact \\
\hline 5, Ma, 14 & c. $4990 \mathrm{C}>\mathrm{T}$ & LOF & $\begin{array}{l}\text { NA, father } \\
\text { unavailable }\end{array}$ & GDD (12Mo) & $\mathrm{N}(10 \mathrm{y})$ & M & I & No, No, No & Cerebellar ataxia, ASD \\
\hline 6, Ma, 31 & c. $1747 \mathrm{C}>\mathrm{T} * \ddagger$ & LOF & father & GDD (12Mo) & NA & M & I & No, No, Yes & Cerebellar ataxia \\
\hline 7, Fe, 28 & c. $1747 \mathrm{C}>\mathrm{T} * \dagger$ & LOF & father & GDD (18Mo) & N (3y) & M & I & No, No, Yes & $\begin{array}{l}\text { Cerebellar ataxia, bucco-linguo-facial dyspraxia, } \\
\text { dystonia; gaze-evoked nystagmus }\end{array}$ \\
\hline 8, Ma, 64 & c. $1747 \mathrm{C}>\mathrm{T} * \ddagger$ & LOF & $\begin{array}{l}\text { NA, } 2 \text { parents } \\
\text { unavailable }\end{array}$ & GDD (NA) & $\begin{array}{l}\text { Progressive cerebellar atrophy } \\
\text { (vermis) }\end{array}$ & M & I & No, Yes (NA), Yes & Cerebellar ataxia \\
\hline $9, \mathrm{Fe}, 3$ & c.2815_2816del \$ & LOF & father & Seizures $(2 \mathrm{Mo})$ & $\begin{array}{c}\text { Cerebral atrophy, bilateral stroke } \\
\text { sequels }\end{array}$ & $\mathrm{S}$ & IV & No, No, No & Pyramidal signs \\
\hline 10, Ma, 8 & c. $835 \mathrm{C}>\mathrm{T}$ & UNK & mother & Hypotonia (4Mo) & $\begin{array}{l}\text { Progressive cerebellar atrophy } \\
\text { (vermis), widening of percerebral } \\
\text { spaces }\end{array}$ & $\mathrm{S}$ & II & $\begin{array}{l}\text { Tremor/myoclonus, No, } \\
\text { No }\end{array}$ & Hypotonia, cerebellar ataxia, ASD; hypermetropia \\
\hline $11, \mathrm{Fe}, 9$ & c. $1082 \mathrm{G}>\mathrm{A} \ddagger$ & UNK & father & GDD $(6 \mathrm{Mo})$ & Progressive cerebellar atrophy & $\mathrm{S}$ & IV & No, No, No & $\begin{array}{l}\text { Hypotonia, cerebellar ataxia; PTU, oculo-motor } \\
\text { apraxia }\end{array}$ \\
\hline $12, \mathrm{Fe}, 20$ & c. $2137 \mathrm{G}>\mathrm{A}$ & GOF & de novo & Jitteriness (1day) & $\begin{array}{c}\text { Progressive cerebellar atrophy, } \\
\text { cerebral atrophy }\end{array}$ & $\mathrm{S}$ & III & Myoclonus, $24 \mathrm{Mo}$, No & $\begin{array}{c}\text { Cerebellar ataxia, pyramidal signs, ASD; gaze- } \\
\text { evoked nystagmus }\end{array}$ \\
\hline 13, Ma, 8 & c. $4046 \mathrm{G}>\mathrm{A}$ & GOF & de novo & Hypotonia (4Mo) & $\begin{array}{c}\text { Progressive cerebellar atrophy, left } \\
\text { lenticulo-caudal and occipital stroke } \\
\text { sequels }\end{array}$ & $\mathrm{S}$ & III & Tremor, $48 \mathrm{Mo}$, Yes & $\begin{array}{l}\text { Cerebellar ataxia, pyramidal signs, hemiparesis, } \\
\text { dystonia; gaze-evoked nystagmus, strabismus }\end{array}$ \\
\hline 14, Ma, 10 & c. $1847 \mathrm{G}>\mathrm{C} ¥$ & UNK & de novo & $\begin{array}{l}\text { Hypotonia } \\
\text { (12Mo) }\end{array}$ & $\begin{array}{l}\text { Progressive cerebellar atrophy } \\
\text { (vermis) }\end{array}$ & M & II & $\begin{array}{l}\text { Tremor/myoclonus, } 7,5 \mathrm{y} \\
\text { Yes }\end{array}$ & Cerebellar ataxia; gaze-evoked nystagmus \\
\hline 15, Ma, 23 & c. $4177 \mathrm{G}>\mathrm{A}$ & UNK & de novo & Jitteriness (1day) & Cerebral atrophy $(2 \mathrm{y})$ & $\mathrm{S}$ & III & $\begin{array}{c}\text { Tremor/myoclonus, } 10 \mathrm{Mo} \text {, } \\
\text { No }\end{array}$ & $\begin{array}{c}\text { Cerebellar ataxia, pyramidal signs; gaze-evoked } \\
\text { nystagmus, strabismus }\end{array}$ \\
\hline 16, Ma, 19 & c. $2137 \mathrm{G}>\mathrm{A}$ & GOF & de novo & Jitteriness (1day) & $\mathrm{N}$ (childhood) & $\mathrm{S}$ & $\mathrm{V}$ & $\begin{array}{l}\text { Tremor/myoclonus, 26Mo, } \\
\text { Yes }\end{array}$ & Pyramidal signs, dystonia, ASD \\
\hline 17, Fe, 20 & c. $4273 \mathrm{G}>\mathrm{T} \ddagger$ & LOF & mother & GDD (12Mo) & $\mathrm{N}(19 \mathrm{y})$ & $\mathrm{M}$ & - & No, No, No & - \\
\hline $18, \mathrm{Fe}, 6$ & c. $4890 \mathrm{G}>\mathrm{A} \ddagger$ & LOF & mother & Seizures (36Mo) & $\mathrm{N}(3 \mathrm{y})$ & - & - & No, No, Yes & - \\
\hline
\end{tabular}

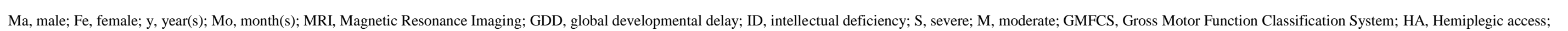

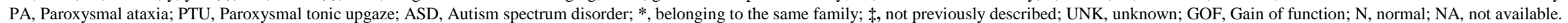



Table 2: Patients electro-clinical features.

\begin{tabular}{|c|c|c|c|c|c|c|c|c|c|}
\hline \multirow{2}{*}{ Patient } & \multirow{2}{*}{$\begin{array}{c}\text { At onset } \\
\text { Type, Age } \\
\text { (Mo) }\end{array}$} & \multicolumn{3}{|c|}{ Follow up } & \multirow{2}{*}{$\begin{array}{c}\text { Status } \\
\text { epilepticus }\end{array}$} & \multicolumn{2}{|c|}{ EEG findings } & \multirow{2}{*}{$\begin{array}{l}\text { Hemiplegic accesses } \\
\text { (duration) }\end{array}$} & \multirow{2}{*}{$\begin{array}{c}\text { Epilepsy } \\
\text { type }\end{array}$} \\
\hline & & Type(s) & Trigger(s) & Frequency & & Interictal activity & Ictal activity & & \\
\hline 1 & $\mathrm{~F}(\mathrm{SE}), 7$ & F : clonic; G: TC, ES; U: MJ & $\begin{array}{l}\text { Fever, viral } \\
\text { infection }\end{array}$ & Weekly & F/G & $\begin{array}{l}\text { SBA, MF sharp waves and SW } \\
\text { complexes }\end{array}$ & F and G SW discharge & $\begin{array}{l}\text { Hemispheric delta } \\
\text { activity (Mo) }\end{array}$ & $\begin{array}{l}\text { Combined } \\
\text { G/F }\end{array}$ \\
\hline 2 & $\mathrm{~F}(\mathrm{SE}), 17$ & F-GT: tonic, atonic; $\mathbf{G}$ : TC, MJ & $\begin{array}{l}\text { Fever, bath, strong } \\
\text { emotions }\end{array}$ & Daily & $\mathrm{F} / \mathrm{G}$ & $\begin{array}{l}\text { SBA, G sharp waves and SW } \\
\text { complexes }\end{array}$ & $\begin{array}{l}\text { G SW discharge, F theta } \\
\text { rhythmic discharge }\end{array}$ & $\begin{array}{l}\text { Hemispheric delta } \\
\text { activity (Weeks) }\end{array}$ & $\begin{array}{l}\text { Combined } \\
\text { G/F }\end{array}$ \\
\hline 3 & $\mathrm{~F}(\mathrm{SE}), 24$ & F-GT: BA +/- autonomic features & $\begin{array}{c}\text { Fever, external } \\
\text { climate changes, } \\
\text { stress }\end{array}$ & Weekly & F & $\begin{array}{l}\text { SBA, F sharp waves and SW } \\
\text { complexes }\end{array}$ & F theta rhythmic discharge & Not recorded & $\mathrm{F}$ \\
\hline 4 & $\mathrm{~F}: \mathrm{BA}, 12$ & $\mathbf{F}$ : versive, BA (+/-automatisms) & 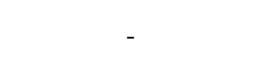 & Daily & - & $\begin{array}{l}\text { SBA, G sharp waves and SW } \\
\text { complexes }\end{array}$ & F beta rhythmic discharge & - & $\mathrm{F}$ \\
\hline 5 & G-TC, 12 & G : absence, TC & Fever & Daily & - & SBA, G SW complexes & 3Hz G SW discharge & - & G \\
\hline 6 & G-TC, 36 & $\mathbf{G}: \mathrm{TC}$ & Fever & Rare & - & $\mathrm{N}$ & Not recorded & - & G \\
\hline 7 & $\begin{array}{c}\text { Atypical } \\
\text { absence, } 36\end{array}$ & $\mathbf{G}:$ atypical absence & - & Daily & - & $\begin{array}{l}\text { SBA, G sharp waves and SW } \\
\text { complexes }\end{array}$ & G SW discharge $(<3 \mathrm{~Hz})$ & - & G \\
\hline 8 & NA, 19 years & G : tonico-clonic ; atypical absence & - & NA & - & SBA, G sharp waves complexes & Not recorded & Not recorded & G \\
\hline 9 & $\mathrm{~F}(\mathrm{SE}), 2$ & $\mathbf{F}$ : clonic & - & Rare & F & $\mathrm{N}$ & F SW discharge & - & $\mathrm{F}$ \\
\hline 10 & $\begin{array}{c}\text { Atypical } \\
\text { absence, } 38\end{array}$ & G : atypical absence & - & Daily & - & $\begin{array}{l}\text { SBA, G sharp waves and SW } \\
\text { complexes }\end{array}$ & Not recorded & - & G \\
\hline 11 & $\begin{array}{l}\text { Atypical } \\
\text { absence, } 36\end{array}$ & G : atypical absence, TC & - & Daily & - & $\begin{array}{l}\text { SBA, G sharp waves and SW } \\
\text { complexes }\end{array}$ & G SW discharge $(<3 \mathrm{~Hz})$ & - & G \\
\hline 12 & G-TC (SE), 12 & F-GT: tonic, atonic, versive & $\begin{array}{l}\text { Fever, bath, } \\
\text { menstruation, noises }\end{array}$ & Weekly & F/G & $\begin{array}{l}\text { SBA; MF sharp waves and SW } \\
\text { complexes, diffuse fast rhythms in } \\
\text { sleep }\end{array}$ & F beta rhythmic discharge & $\begin{array}{l}\text { Hemispheric delta } \\
\text { activity (Mo) }\end{array}$ & $\begin{array}{l}\text { Combined } \\
\text { G/F }\end{array}$ \\
\hline 13 & $\mathrm{~F}(\mathrm{SE}), 48$ & F-GT: clonic; $\mathbf{U}$ : BA & Fever & Daily & F/G & SBA & $\mathrm{F}$ delta periodic complexes & $\begin{array}{l}\text { Hemispheric theta } \\
\text { rhythmic activity (Mo) }\end{array}$ & $\mathrm{U}$ \\
\hline 14 & G-TC, 6 years & $\mathbf{G}: \mathrm{TC} ; \mathbf{F}:$ clonic & $\begin{array}{l}\text { Head trauma, viral } \\
\text { infection }\end{array}$ & Rare & $\mathrm{F}$ & $\mathrm{G}$ sharp waves and $\mathrm{SW}$ complexes & F SW discharge & $\begin{array}{l}\text { Abnormal background } \\
\text { structure (Mo) }\end{array}$ & $\begin{array}{l}\text { Combined } \\
\text { G/F }\end{array}$ \\
\hline 15 & G-TC (SE), 4,5 & F-GT: clonic; $\mathbf{G}:$ TC, tonic; $\mathbf{U}: \mathrm{BA}$ & Fever, head trauma & Weekly & F/G & $\begin{array}{c}\text { SBA, G sharp waves and SW } \\
\text { complexes (bifrontal predominance) }\end{array}$ & $\mathrm{G}$ beta rhythmic discharge & $\begin{array}{l}\text { Hemispheric delta } \\
\text { activity (Hours) }\end{array}$ & $\begin{array}{l}\text { Combined } \\
\text { G/F }\end{array}$ \\
\hline 16 & G-TC (SE), 12 & $\begin{array}{l}\text { G : TC, tonic; F: clonic, motor } \\
\text { automatisms; } \mathbf{U}: \text { BA, MJ }\end{array}$ & Fever, stress & Daily & $\mathrm{F} / \mathrm{G}$ & $\begin{array}{l}\text { G or MF SW complexes, diffuse fast } \\
\text { rhythms in sleep }\end{array}$ & $\begin{array}{l}\text { F theta rhythmic activity, } \mathrm{G} \\
\text { beta rhythmic discharge }\end{array}$ & $\begin{array}{l}\text { Hemispheric delta } \\
\text { activity (Hours) }\end{array}$ & $\begin{array}{c}\text { Combined } \\
\mathrm{G} / \mathrm{F}\end{array}$ \\
\hline 17 & Absence, 36 & G : absence & - & Daily & - & G SW complexes & $3 \mathrm{~Hz}$ G SW discharge & - & G \\
\hline 18 & Absence, 36 & G : absence & - & Daily & - & G and MF SW complexes & 3Hz G SW discharge & - & $\mathrm{G}$ \\
\hline
\end{tabular}

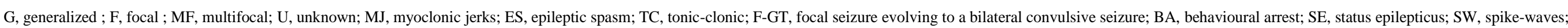
SBA, slow background activity; Mo, month(s); N, normal; NA, not available. 

Table 3: Therapeutic profiles and seizure outcomes of CACNA1A epileptic patients.

\begin{tabular}{|c|c|c|c|c|c|c|c|c|c|}
\hline \multirow[b]{2}{*}{ Patient } & \multicolumn{3}{|c|}{ AEDs } & \multicolumn{6}{|c|}{$\begin{array}{c}\text { Other } \\
\text { treatments }\end{array}$} \\
\hline & $\begin{array}{l}\text { Seizure } \\
\text { free }\end{array}$ & Seizure reduction & No effect & Actual AED & $\begin{array}{l}\text { Seizure } \\
\text { free }\end{array}$ & $\begin{array}{c}\text { Seizure } \\
\text { reduction }\end{array}$ & No effect & Actual treatments & Epilepsy outcome \\
\hline 1 & & TPM, VPA, LTG & LEV, BZD & VPA, LTG & & & ACTZ, Pyridoxine, KD & ACTZ, Pyridoxine & Refractory \\
\hline 2 & & TPM, LCS, CBZ, VPA & LEV, BZD, LTG & VPA, LCS, BZD & ACTZ & & $\mathrm{KD}$ & $\mathrm{ACTZ}$ & Refractory \\
\hline 3 & & CBZ, TPM, LCS & VPA, LEV & TPM, LCS & & & ACTZ, Flunarizine & - & Refractory \\
\hline 4 & & LEV, TPM & & LEV, TPM & & & & - & Refractory \\
\hline 5 & TPM & ESM, VPA & LTG & TPM, VPA & & & & - & Fluctuation course \\
\hline 6 & & & & - & & & & - & Early seizure freedom \\
\hline 7 & & VPA & LTG, ESM & LTG & & $\mathrm{ACTZ}$ & $\mathrm{KD}$ & ACTZ & Delayed seizure freedom \\
\hline 8 & & ТРМ, РB & & - & & $\mathrm{ACTZ}$ & & ACTZ & Delayed seizure freedom \\
\hline 9 & LEV & & & LEV & & & & - & Early seizure freedom \\
\hline 10 & & VPA, OXC & $\mathrm{CBZ}$ & VPA, OXC & & & & - & Refractory \\
\hline 11 & & OXC, TPM, LTG & ESM & TPM, LTG & & & & - & Refractory \\
\hline 12 & & LEV, ZNS & BZD, VPA, OXC, CBZ & OXC, ZNS, BZD, LEV & & & Pyridoxine, VNS & VNS & Refractory \\
\hline 13 & & LEV & & LEV & & Flunarizine & Pyridoxine & Pyridoxine, Flunarizine & Fluctuation course \\
\hline 14 & LEV & & & LEV & & & & - & Early seizure freedom \\
\hline 15 & & TPM, VPA, PB & CBZ, BZD, LTG, LEV, ESM & VPA, TPM, PB, BZD, ESM & & & & - & Refractory \\
\hline 16 & & LTG, TPM, OXC, LEV & VPA, CBZ, BZD, ZNS & LTG, ZNS, BZD & & & Pyridoxine, KD, VNS & Pyridoxine & Refractory \\
\hline 17 & & TPM, LTG, ESM & VPA, LEV & TPM & & $\mathrm{KD}$ & VNS & - & Refractory \\
\hline 18 & & VPA, LTG & ESM $^{*}$ & VPA, LTG & & & & - & Refractory \\
\hline
\end{tabular}

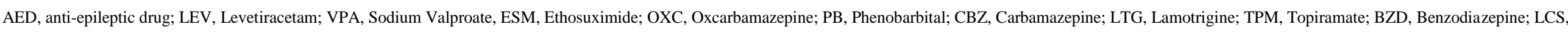
Lacosamide; ZNS, Zonisamide; VNS, vagus nerve stimulation; KD, ketogenic diet; ACTZ, Acetazolamide; * stopped because of poor tolerability. 
S1 : Supplementary genetic features.

\begin{tabular}{|c|c|c|c|c|c|c|c|}
\hline Patient & $\begin{array}{c}\text { Mutation } \\
\text { (NM_001127221.1) }\end{array}$ & Protein change & $\begin{array}{l}\text { Previous published } \\
\text { cases }\end{array}$ & Domain & Type & $\begin{array}{l}\text { GnomAD } \\
\text { database }\end{array}$ & $\begin{array}{l}\text { CADD } \\
\text { score }\end{array}$ \\
\hline 10 & c. $835 \mathrm{C}>\mathrm{T}$ & p.(Arg279Cys) & $\begin{array}{l}\text { Maksemous et al. 2016, } \\
\text { Angelini et al. } 2018\end{array}$ & $\begin{array}{l}\text { I S5 - I } \\
\text { S6 }\end{array}$ & Missense & Absent & 26,2 \\
\hline 11 & c. $1082 \mathrm{G}>\mathrm{A} \ddagger$ & p.(Gly361Glu) & - & $\begin{array}{l}\text { III S5 - } \\
\text { III S6 }\end{array}$ & Missense & Absent & 33 \\
\hline $6,7,8$ & c. $1747 \mathrm{C}>\mathrm{T} *$ & p. $\left(\operatorname{Arg} 583^{*}\right)$ & - & II S4, t & Non-sense & Absent & 38 \\
\hline 14 & c. $1847 \mathrm{G}>\mathrm{C}$ & p.(Ser616Thr) & - & II S5, t & Missense & Absent & 25,7 \\
\hline 4 & c. $2006 \mathrm{~A}>\mathrm{C} *$ & p.(Asp669Ala) & - & $\begin{array}{l}\text { II S5 - II } \\
\text { S6 }\end{array}$ & Missense & Absent & 24 \\
\hline $2,3,12,16$ & c. $2137 \mathrm{G}>\mathrm{A}$ & p.(Ala713Thr) & $\begin{array}{l}\text { Epi4k 2016, Balck et al. } \\
\text { 2017, Jiang et al. } 2019\end{array}$ & II S6, t & Missense & Absent & 29,3 \\
\hline 9 & c.2815_2816del $\ddagger$ & p.(Gly939Glnfs*128) & - & $\begin{array}{l}\text { II S6 - III } \\
\text { S1 }\end{array}$ & Non-sense & Absent & - \\
\hline 13 & c. $4046 \mathrm{G}>\mathrm{A}$ & p.(Arg1349Gln) & Knienim et al. 2011 & III S4, t & Missense & Absent & 32 \\
\hline 15 & c. $4177 \mathrm{G}>\mathrm{A}$ & p.(Val1393Met) & Butler et al. 2017 & III S5, t & Missense & Absent & 28 \\
\hline 17 & c. $4273 \mathrm{G}>\mathrm{T} \ddagger$ & p.(Glu1425*) & - & $\begin{array}{c}\text { II S6 - III } \\
\text { S1 }\end{array}$ & Non-sense & Absent & 44 \\
\hline 18 & c. $4890 \mathrm{G}>\mathrm{A} \$$ & p. $\left(\operatorname{Trp} 1630^{*}\right)$ & - & IV S3, t & Non-sense & Absent & 46 \\
\hline 5 & c. $4990 \mathrm{C}>\mathrm{T}$ & p. $(\operatorname{Arg} 1664 *)$ & Mantuano et al. 2010 & IV S4, $\mathrm{t}$ & Non-sense & Absent & 39 \\
\hline 1 & c. $5083 \mathrm{G}>\mathrm{C}$ & p.(Val1695Leu) & - & IV S5, t & Missense & Absent & 23,3 \\
\hline
\end{tabular}

\$, not previously described; $\mathrm{t}$, transmembrane domain. 


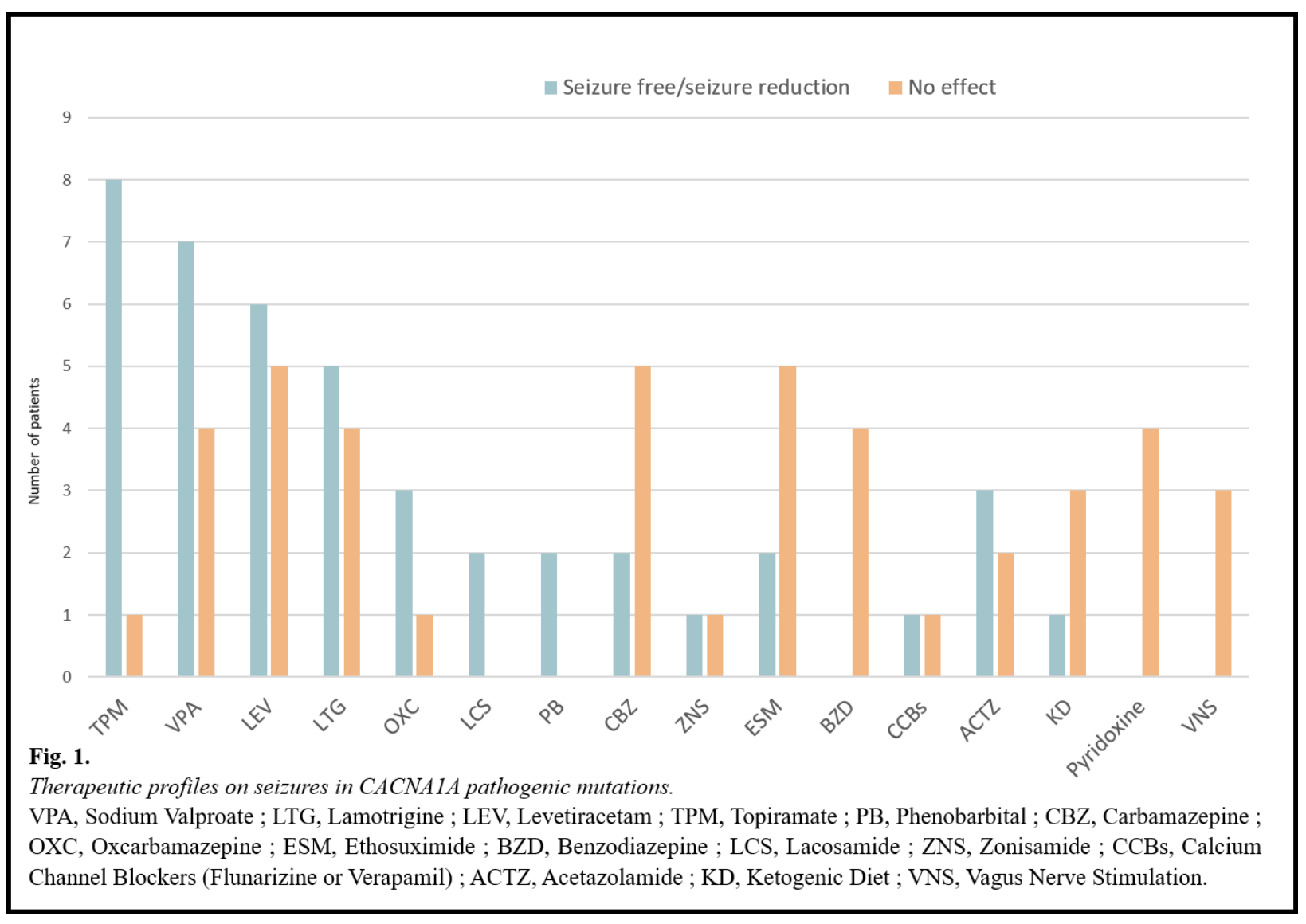



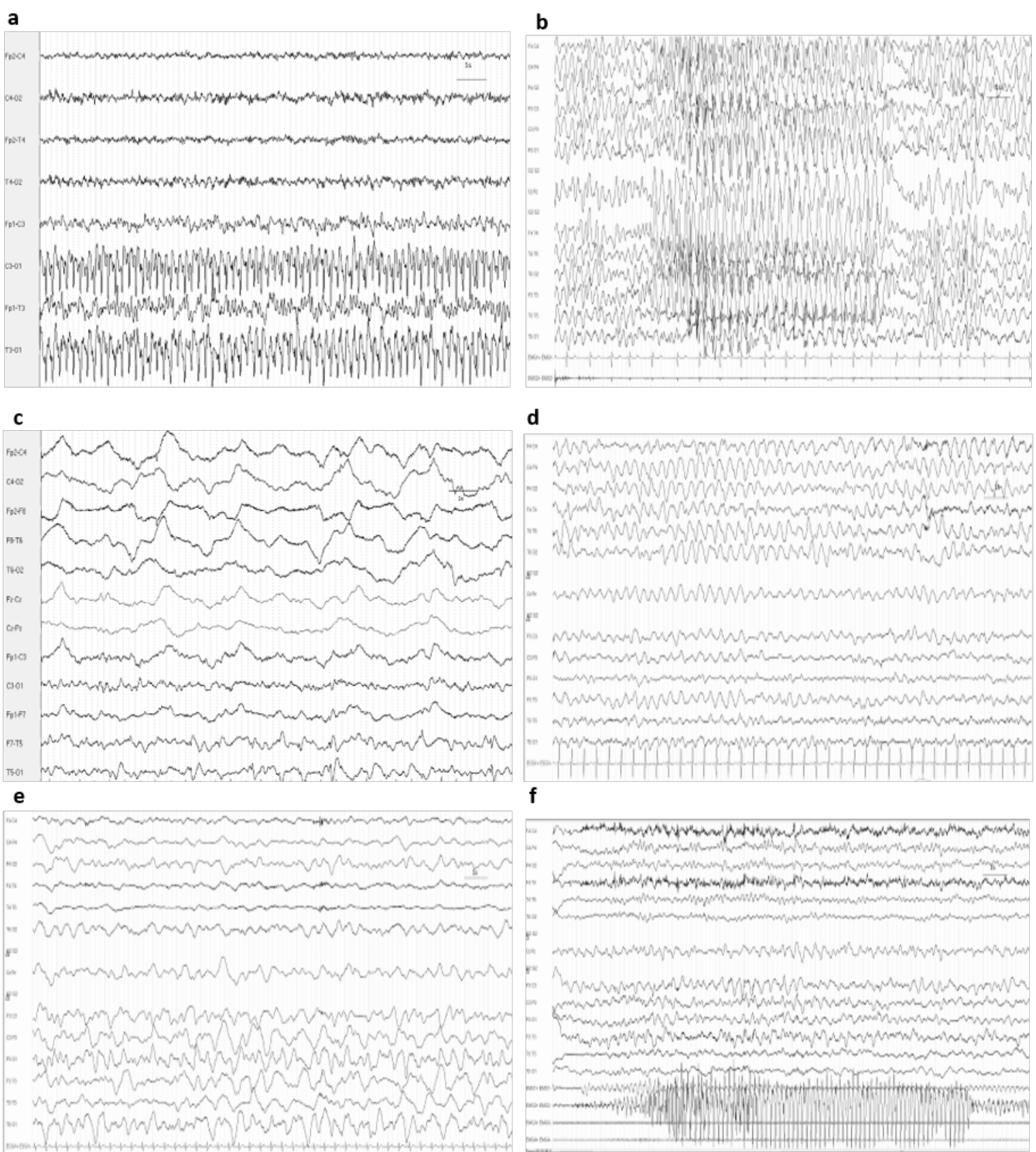

\section{Fig. 2.}

$70 \mathrm{~Hz}-100 \mathrm{uV} / \mathrm{cm}$

Examples of EEG patterns in epileptic patients with CACNAIA pathogenic mutations. Cases 1 (a,c), 11 (b) and 13 (d-f).

(a): Left occipital spike-waves discharge during a right clonic SE. (b): Diffuse 2,5Hz spike-waves discharge concomitant with behavioural arrest, consistent to an atypical absence seizure. (c): Right hemispheric delta activity concomitant with persistent consciousness impairment and left hemiplegia, corresponding to a left hemiplegic access. Note the left temporo-occipital focus, consistent to a previous stroke in this case. (d): Right-lateralized theta rhythmic activity persisting a month after a left hemiplegic attack. (e): Left fronto-temporal delta activity with triphasic complexes during a first hemiplegic access with "encephalitis-like" presentation. (f): Episode of bilateral limb jerks recorded on surface EMG, with slow left-sided rhythmic activity but absence of epileptiform discharges, corresponding to non-epileptic movements. 

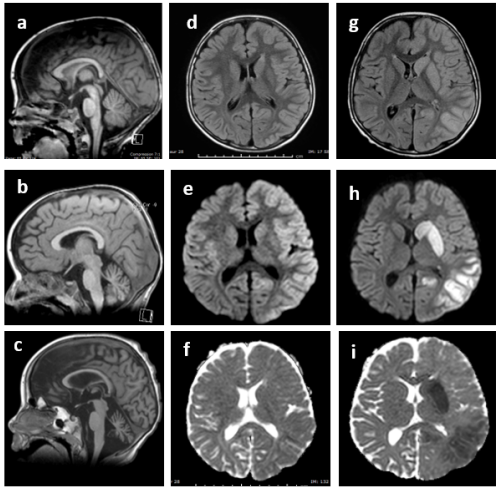

Fig. 3.

MRI findings in epileptic patients with CACNA1A pathogenic mutations. Progressive cerebellar atrophy on three T1 sagittal images performed at the age of 1 (a), 2 (b) and 4 years (c) in case 1 . Strokelike lesions in case 13 (d-i). Axial images performed at the subacute phase of a right HM attack (d-f), showing left cortical hyperintensity on FLAIR (d) and DWI (e) corresponding to edema but no signal change on the ADC map (f). Axial images performed 7 days after (gi), considering persistent right hemiparesis and homolateral seizures. FLAIR showed left cortical hemispheric hyperintensity (g), and DWI showed left lenticulo-caudal, putaminal and parietal cortical hyperintensities that crossed vascular territories (h) with concomitant signal reduction ranges on the ADC map (i). 


\section{Highlights :}

- CACNA1A variants result in 2 different electro-clinical phenotypes: intractable seizures associated with early and recurrent status epilepticus and hemiplegic accesses, and early onset refractory absence seizures.

- Functional studies suggest that the first electro-clinical phenotype is associated with a gain of function, and that the second one is associated with a loss of function.

- Epilepsy related with CACNA1A variants is associated with cerebellar dysfunction and early neurodevelopmental impairment.

- Drug resistance is very frequent in epileptic CACNA1A patients. 


\section{DISCLOSURE}

None of the authors has any conflict of interest to disclose. 